PSYCHOMETRIKA-VOL. 14, NO.

MARCH, 1949

\title{
A FACTORIAL APPROACH TO JOB FAMILIES
}

\author{
Clyde H. CoOmbs ANd George A. SATter \\ UNIVERSITY OF MICHIGAN*
}

This is an experimental study of the application of factor analysis to a new domain-the formation of job families. Correlations between jobs are computed from the formula based on the number of common elements between two variables and the job analyses provide the basic data on the presence or absence of the elements. A firstorder general factor and four common factors are obtained in a small sample of twenty occupations. Tentative interpretations are made and implications for job analysis and the formation of job families are pointed out.

\section{The Nature of the Problem}

The determination of the dimensionality of the world of work and the composition of job families presents intriguing methodological problems. The organization of occupations into job families has generally been accomplished by the exercise of judgment, of expert and knowing judges perhaps, but still not objective and verifiable. This study is a report of an attempt to adapt job analyses to the techniques of multiple-factor analysis.

A psychological analysis of the domain of occupations leads to the conclusion that there is not necessarily any single set of job families, but rather that there may be a different solution for each purpose which job families serve.

For purposes of facilitating certain aspects of the work of Selective Service during World War II, for example, three families of occupations were created and used:critical, essential, and the remainder. The critical family was comprised of those occupations which had long training times, which were essential to a war activity, and in which there were national shortages. The essential family, similarly, was defined by occupations in an essential war activity, but in general these occupations required less training time than the members of the critical family.

This illustrates the basic philosophy underlying the construction of job families. They are created to facilitate or simplify the accom-

*The analysis the results of which are reported here was made possible by the Bureau of Psychological Services, Institute for Human Adjustment, Horace H. Rackham School of Graduate Studies, University of Michigan. 
plishment of particular objectives. Another objective during the recent war was to expand the employment of women. Consequently, another family was created-a family comprised of those jobs which possessed the characteristics of being suitable for women.

There must be a very great variety of objectives which would be served by relevant job families. A few might be listed as follows:

1) vocational guidance of individuals who are contemplating training for, or immediate entrance into, an occupational area,

2) vocational guidance of various handicapped groups,

3) the establishment of vocational training curricula,

4) vertical transfer of personnel-promotion within the organizational unit,

5) horizontal transfer of personnel, as in the case of the utilization of civilian skills in military occupations,

6) the development of an interest inventory,

7) the development of a differential aptitude test battery,

8) a basis for the organization of unions,

9) occupational representation in a legislature, as Toynbee* suggests, and

10) the establishment of wages and salaries.

To attain any one of these objectives, an appropriate system of job families would be desirable. To establish an appropriate set of families, however, requires first a job analysis designed to secure that kind of information about a job which is relevant to that objective. Having done that, an analysis of the sort carried out in this study appears to be an appropriate way to determine relevant and useful job families.

There is nothing to be gained here by summarizing the various systems on the basis of which jobs have been classified into groups or families. Shartle's $\nmid$ book and an article by Cardall $\ddagger$ describes some of them.

Contrary to the above requisites for the formation of meaningful and useful job families, the present study was based on job analyses of a standard, almost universal character. The job analyses were made for an entirely different purpose without any thought of their appropriateness for such a study as this. Consequently, this study is primarily of methodological and theoretical interest. This study was carried out as a pilot investigation to determine the feasibility of this method of analysis.

\footnotetext{
*Toynbee, Arnold J. A study of history. New York: Oxford University Press, 1946, p. 617 .

†Shartle, Carroll L. Occupational information. New York: Prentice-Hall, Inc., 1946 , p. 339 .

tCardali, Alfred J. A test for primary business interests based on a functional occupational classification. Educ. psychol. Meas., 1942, 2, 113-138.
} 


\section{The Job Analysis}

The data which form the basis of this investigation were collected in the course of evaluating 70 jobs in a large, mid-western paper mill. The methods of study were modeled after those developed and popularized by the United States Employment Service and involved sending trained job analysts to the departments of the plant employing personnel in the job classifications up for evaluation. The analyst interviewed and observed. He interviewed the employee on the job, his immediate supervisor, and the departmental head under whose jurisdiction the job fell; he observed the employee as he carried out the routines of his job. On the basis of these observations and the information collected in the interviews, he prepared a job description; he also assisted, with the immediate supervisor and the department head, in the preparation of a specification for the job. It is these specifications which supply the raw materials for the current analysis.

The specifications were recorded in the form of a "rating" on a standard specification sheet. The sheet made provision for recording 18 such judgments of various aspects of the skills and knowledges required by the jobs. Each of the 18 items was prefaced by a brief statement defining a particular skill or knowledge area, and this was followed by three or four alternative phrases or statements of various degrees of skill or knowledge. In this investigation these alternatives are regarded as elements - characteristics which make jobs alike or different, i.e., generate correlation between them. In all there were 104 such elements distributed in the following manner:

\begin{tabular}{lc}
\hline \multicolumn{1}{c}{ Category } & $\begin{array}{c}\text { Possible no. } \\
\text { of elements }\end{array}$ \\
\hline educational skills & 18 \\
work skilis & 42 \\
application skills & 9 \\
social and personal skills & 19 \\
activity distribution & 16 \\
\hline Total & $\mathbf{1 0 4}$ \\
\hline
\end{tabular}

\section{The Correlation Matrix}

In order to reduce the labor involved, the 70 occupations included in the job analysis were reduced to 54 by the arbitrary elimination of obvious doublets. For example, Senior Invoice Clerk was retained and Junior Invoice Clerk was dropped ; Librarian was retained and Assistant Librarian was dropped.

The correlations between the 54 occupations were computed on the 
basis of the number of common elements by the use of the formula:*

$$
r_{a b}=\frac{n_{c}}{\sqrt{\left(n_{a}+n_{c}\right)\left(n_{b}+n_{c}\right)}}
$$

where

$$
\begin{aligned}
& n_{c}=\text { number of elements common to jobs } a \text { and } b . \\
& n_{a}=\text { number of elements in job } a \text { not in job } b . \\
& n_{b}=\text { number of elements in job } b \text { not in job } a .
\end{aligned}
$$

Inasmuch as this was to serve as a pilot study, the matrix of correlations of 54 jobs was of too large an order to factor. Consequently, a submatrix of order $20 \times 20$ was selected. The 20 variables whose intercorrelations were factored were selected on the basis of having the lowest sums of correlations with all the other variables. This was done in an effort to select 20 variables out of the original 54 which would tend to span the same space as nearly as possible and thereby reveal some of the corners of the total configuration.

Table 1 contains the basic data on which the correlations are

\begin{tabular}{|c|c|c|c|c|c|c|c|c|c|c|c|c|c|c|c|c|c|c|c|c|c|}
\hline & $n$ & 1 & 2 & 3 & 4 & 5 & 6 & 7 & 8 & 9 & 10 & 11 & 12 & 13 & 14 & 15 & 16 & 17 & 18 & 19 & 20 \\
\hline$\overline{1}$ & 43 & & & & & & & & & & & & & & & & & & & & \\
\hline 2 & 53 & 35 & & & & & & & & & & & & & & & & & & & \\
\hline 3 & 42 & 31 & 31 & & & & & & & & & & & & & & & & & & \\
\hline 4 & 49 & 35 & 40 & 32 & & & & & & & & & & & & & & & & & \\
\hline 5 & 54 & 26 & 34 & 27 & 31 & & & & & & & & & & & & & & & & \\
\hline 6 & 48 & 31 & 35 & 30 & 37 & 32 & & & & & & & & & & & & & & & \\
\hline 7 & 45 & 22 & 25 & 23 & 25 & 29 & 27 & & & & & & & & & & & & & & \\
\hline 8 & 74 & 34 & 41 & 33 & 39 & 40 & 37 & 30 & & & & & & & & & & & & & \\
\hline 9 & 57 & 28 & 32 & 31 & 31 & 39 & 31 & 28 & 45 & & & & & & & & & & & & \\
\hline 10 & 35 & 20 & 21 & 24 & 21 & 22 & 21 & 19 & 23 & 24 & & & & & & & & & & & \\
\hline 11 & 44 & 23 & 27 & 25 & 25 & 29 & 27 & 24 & 33 & 32 & 24 & & & & & & & & & & \\
\hline 12 & 39 & 22 & 24 & 24 & 24 & 30 & 24 & 24 & 27 & 28 & 22 & 25 & & & & & & & & & \\
\hline 13 & 36 & 26 & 29 & 28 & 29 & 25 & 30 & 22 & 31 & 25 & 19 & 22 & 19 & & & & & & & & \\
\hline 14 & 38 & 25 & 26 & 26 & 27 & 25 & 28 & 25 & 27 & 25 & 20 & 21 & 21 & 26 & & & & & & & \\
\hline 15 & 40 & 22 & 24 & 25 & 25 & 24 & 26 & 24 & 26 & 26 & 22 & 21 & 20 & 24 & 28 & & & & & & \\
\hline 16 & 71 & 35 & 35 & 35 & 42 & 42 & 39 & 29 & 57 & 45 & 25 & 32 & 28 & 31 & 28 & 27 & & & & & \\
\hline 17 & 62 & 28 & 31 & 30 & 30 & 39 & 32 & 30 & 45 & 42 & 22 & 32 & 27 & 26 & 28 & 27 & 41 & & & & \\
\hline 18 & 70 & 26 & 34 & 29 & 32 & 43 & 34 & 29 & 45 & 44 & 23 & 31 & 28 & 29 & 27 & 26 & 44 & 43 & & & \\
\hline 19 & 39 & 22 & 26 & 23 & 24 & 29 & 24 & 23 & 30 & 29 & 22 & 26 & 25 & 19 & 19 & 20 & 32 & 27 & 29 & & \\
\hline 20 & 38 & 23 & 29 & 26 & 26 & 27 & 25 & 23 & 30 & 27 & 22 & 26 & 22 & 23 & 20 & 22 & 31 & 28 & 28 & 25 & \\
\hline
\end{tabular}
based. The first column, labeled $n$, indicates the total number of elements for each variable or job. The other cells of the matrix con-

TABLE 1

*Peters, C. C. and Van Voorhis, W. R. Statistical procedures and their mathematical bases. New York: McGraw-Hill Book Company, Inc., 1940, p. 122. 


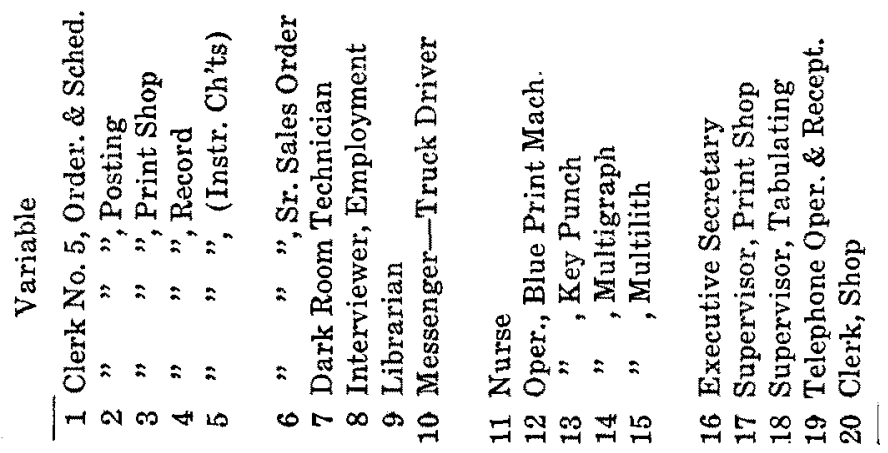


tain the number of elements common to the pair of jobs designated by that row and that column.

The variables selected and their matrix of intercorrelations are given in Table 2.

\section{The Factor Analysis}

The correlation matrix was factored by the complete centroid method to six factors, at which point the residuals were all quite small. The centroid matrix was rotated to a satisfactory simple structure with four planes which had appreciable variance, one residual factor, and one first-order general factor. Both the residual factor and the first-order general factor were set orthogonal to each other and to the other four planes.

TABLE 3

The Centroid Factor Loadings

\begin{tabular}{rrrrrrrr}
\hline & \multicolumn{1}{c}{ I } & II & III & IV & V & VI & \multicolumn{1}{c}{$h^{2}$} \\
\hline 1 & .780 & -.278 & -.137 & .187 & -.059 & .049 & .743 \\
2 & .795 & -.170 & -.181 & .140 & .222 & -.093 & .763 \\
3 & .818 & -.208 & .033 & .100 & -.116 & -.109 & .737 \\
4 & .817 & -.253 & -.233 & .140 & .070 & .129 & .810 \\
5 & .796 & .256 & -.073 & -.088 & .158 & .073 & .737 \\
& & & & & & & \\
6 & .817 & -.173 & -.144 & -.056 & .127 & .065 & .737 \\
7 & .710 & .053 & .151 & -.169 & .088 & .121 & .558 \\
8 & .783 & .177 & -.291 & .080 & -.142 & -.028 & .756 \\
9 & .799 & .264 & -.080 & -.035 & -.142 & -.062 & .736 \\
10 & .699 & -.028 & .343 & .139 & -.088 & -.049 & .634 \\
& & & & & & & \\
11 & .753 & .151 & .166 & .103 & .020 & -.136 & .591 \\
12 & 734 & .115 & .225 & .046 & .097 & .132 & .614 \\
13 & .794 & -.260 & -.040 & -.091 & .019 & -.103 & .708 \\
14 & .763 & -.270 & .114 & -.282 & -.081 & .095 & .754 \\
15 & .726 & -.203 & .214 & -.232 & -.132 & .025 & .685 \\
& & & & & & & \\
16 & .805 & .147 & -.239 & .093 & -.180 & .145 & .768 \\
17 & .767 & .227 & -.046 & -.173 & -.103 & -.083 & .682 \\
18 & .744 & .236 & -.140 & -.195 & .071 & -.129 & .672 \\
19 & .747 & .191 & .192 & .185 & .091 & .093 & .674 \\
20 & .772 & .029 & .144 & .148 & .095 & -.133 & .648 \\
\hline
\end{tabular}

The centroid factor matrix $\left(F_{c}\right)$ is given in Table 3 , and the final oblique factor matrix $(V)$ is given in Table 4. Table 5 contains the transformation matrix $(\Lambda)$ leading from the centroid matrix $\left(F_{c}\right)$ to the final rotated matrix $(V)$ by the equation 
CLYDE H. COOMBS AND GEORGE A. SATTER

TABLE 4

The Final Rotated Matrix of Factor Loadings

\begin{tabular}{rrrrrrr}
\hline \hline & \multicolumn{1}{c}{$\mathrm{A}$} & $\mathrm{B}$ & $\mathrm{C}$ & \multicolumn{1}{c}{$\mathrm{D}$} & $\mathrm{E}$ & \multicolumn{1}{c}{$\mathrm{F}$} \\
\hline 1 & -.019 & .063 & .178 & .456 & .561 & -.032 \\
2 & -.034 & .050 & -.006 & .380 & .731 & -.162 \\
3 & .039 & .183 & .245 & .232 & .597 & -.118 \\
4 & -.031 & -.049 & .129 & .517 & .663 & .015 \\
5 & .218 & .006 & -.025 & .062 & .799 & .160 \\
& & & & & & \\
6 & .008 & -.086 & .191 & .310 & .740 & -.022 \\
7 & .024 & .056 & .234 & -.051 & .683 & .153 \\
8 & .416 & -.016 & -.054 & .306 & .604 & .059 \\
9 & .407 & .081 & .030 & .060 & .654 & .086 \\
10 & -.055 & .420 & .204 & -.052 & .527 & .049 \\
& & & & & & \\
11 & .117 & .330 & .014 & -.033 & .654 & .001 \\
12 & -.029 & .254 & .104 & -.022 & .675 & .218 \\
13 & .011 & -.006 & .302 & .211 & .669 & -.181 \\
14 & -.022 & -.076 & .540 & .064 & .628 & .009 \\
15 & -.001 & .051 & .508 & -.036 & .574 & -.002 \\
& & & & & & \\
16 & .350 & -.018 & .025 & .338 & .596 & .216 \\
17 & .382 & .011 & .115 & -.025 & .667 & .039 \\
18 & .353 & -.063 & .011 & .008 & .735 & -.038 \\
19 & .013 & .344 & -.032 & .027 & .667 & .223 \\
20 & .005 & .323 & .025 & .058 & .681 & -.053 \\
\hline
\end{tabular}

TABLE 5

The Direction Cosines of the Final Reference Vectors

\begin{tabular}{rrrrrrr}
\hline \hline & $\mathrm{A}$ & $\mathrm{B}$ & \multicolumn{1}{c}{$\mathrm{C}$} & \multicolumn{1}{c}{$\mathrm{D}$} & \multicolumn{1}{c}{$\mathrm{E}$} & \multicolumn{1}{c}{ F } \\
\hline I & .14 & .12 & .18 & .18 & .85 & .04 \\
II & .60 & .16 & -.57 & -.42 & .13 & .40 \\
III & -.47 & .69 & .34 & -.71 & .01 & .15 \\
IV & -.24 & .64 & -.57 & .47 & -.19 & .09 \\
V & -.53 & -.03 & -.39 & -.02 & .47 & -.13 \\
VI & -.25 & -.26 & .19 & .26 & -.02 & .89 \\
\hline
\end{tabular}

TABLE 6

Intercorrelations of the Final Reference Vectors

\begin{tabular}{rrrrrrr}
\hline & $\mathrm{A}$ & $\mathrm{B}$ & $\mathrm{C}$ & $\mathrm{D}$ & $\mathrm{E}$ & $\mathrm{F}$ \\
\hline $\mathrm{A}$ & 1.00 & & & & & \\
$\mathrm{~B}$ & -.28 & .99 & & & & \\
$\mathrm{C}$ & -.18 & -.24 & .99 & & & \\
$\mathrm{D}$ & -.06 & -.30 & -.18 & 1.01 & & \\
$\mathrm{E}$ & .00 & .00 & .00 & .01 & 1.00 & \\
$\mathrm{~F}$ & .00 & .00 & .00 & .01 & .00 & .99 \\
\hline
\end{tabular}




$$
V=F_{c} \Lambda .
$$

The intercorrelations of the final reference vectors are given in Table 6.

The direction cosines of the primary reference vectors, their intercorrelations, and the projections of the variables on the primaries were computed but do not add materially to the interpretations of the study and for this reason are not reproduced here.

\section{Identification of Factors}

Factor A: Self-responsible jobs

The principal jobs and their projections on Factor A are shown in the table below:

\begin{tabular}{rlc}
\hline No. & \multicolumn{1}{c}{ Name } & $\begin{array}{c}\text { Loading } \\
\text { on } \mathrm{A}\end{array}$ \\
\hline 8 & empleyment interviewer & .42 \\
9 & librarian & .41 \\
17 & print shop supervisor & .38 \\
16 & executive secretary & .35 \\
18 & tabulating supervisor & .35 \\
\hline
\end{tabular}

These jobs are all characterized by the individual's independence and self-responsibility on the job, dealing with individuals outside of trie company, a relatively high order of educational skills, and some administrative and supervisory competence.

Factor B: Routine, entry occupations

The major projections on Factor $\mathrm{B}$ were the following:

\begin{tabular}{llc}
\hline No. & \multicolumn{1}{c}{ Name } & $\begin{array}{c}\text { Loading } \\
\text { on } \mathrm{B}\end{array}$ \\
\hline 10 & messenger-truck driver & .42 \\
19 & tele. oper. \& recept. & .34 \\
11 & nurse & .33 \\
20 & shop clerk & .32 \\
\hline
\end{tabular}

The basis for the common factor variance of this cluster is not clear. These jobs seem to have little in common except that they are comparatively routine and, in this organization, were classified as "entry" jobs. 
Factor C: Skilled machine operation jobs

The jobs and loadings characterizing this factor are as follows:

\begin{tabular}{clc}
\hline \hline No. & \multicolumn{1}{c}{ Name } & $\begin{array}{c}\text { Loading } \\
\text { on } \mathrm{C}\end{array}$ \\
\hline 14 & multigraph operator & .54 \\
15 & multilith operator & .51 \\
13 & key punch operator & .30 \\
\hline
\end{tabular}

These jobs all require training on the job and involve a high level of skill in machine operation. This latter characteristic is in contrast to the activities involved in operating blueprinting machines.

Factor D: Clerical jobs

This factor is characterized by the following occupations:

\begin{tabular}{rlc}
\hline \hline No. & \multicolumn{1}{c}{ Name } & $\begin{array}{c}\text { Loading } \\
\text { on D }\end{array}$ \\
\hline 4 & record clerk & .52 \\
1 & ordering \& sched. clerk & .46 \\
2 & posting clerk & .38 \\
16 & executive secretary & .34 \\
6 & sr. sales order clerk & .31 \\
8 & employment interviewer & .31 \\
\hline
\end{tabular}

These occupations are all clerical in nature, characterized by a moderate to high degree of educational skills, calling for neat appearance, and involving such activities as those of filing, posting, and recording.

Factor $E$

This factor is a first-order general factor entering into every occupation included in the factor analysis. There are several possible ways of accounting for this factor. The job analyses used as the basis for generating the correlations tended to be of a general nature rather than highly itemized and specific. This would increase the apparent similarity of the jobs and their intercorrelations and consequently would generate a general factor. On the other hand, a general factor might appear even with a highly itemized job analysis. The implication would be that these occupations are a lot more alike than is sometimes thought, particularly by vocational guidance technicians. 


\section{Factor $F$}

This is the residual factor and is of no psychological interest or significance.

\section{Discussion}

This study has certain definite limitations which should be pointed out.

No first factor analysis of a very large domain should be regarded as definitive when it is based on a sample of 20 . The structure revealed may be regarded as a significant structure for these 20 variables and perhaps for the 70 from which they were selected. But in view of the thousands of different occupations, no small sample suitable for factor analysis by present methods is apt to reveal a structure suitable for the universe of jobs.

Second, the job analyses themselves, as previously pointed out, should be detailed and specific and designed for the particular purposes the job family structure is to serve. The more superficial, verbal, and judgmental the job analyses, the more they will tend to be correlated and this can give rise to a first-order general factor that is, at least in part, an artifact.

Third, the suitability of the correlation formula used is seriously open to question. The assumptions involved in the use of the formula are numerous and include the following: that the contributions of the elements are additive, uncorrelated, equally potent, and equally likely to be present or absent, and further that the total variances of the variables are equal. Without doubt, these assumptions are violated and to an unknown degree. For example, the elements are undoubtedly correlated, some positively and some negatively.

In general, effects of this sort might be expected to enhance or depress a general factor, correlations between reference vectors, and the error variance, but to have less effect on the ultimate interpretations of the factors obtained by means of simple structure. Other methods of correlation not involving these assumptions could be tried and the logic of factor analysis adapted to the type of correlation.

Perhaps the best approach of all would be to begin with the obverse problem of factoring job elements and then to proceed with new job analyses based on a set of independent elements. 